\title{
Study on Change Rules of Factors Affecting Gas Loss during Coalbed Air Reverse Circulation Sampling
}

\author{
Demin Chen $\left(\mathbb{D},{ }^{1,2,3}\right.$ Wei Long $\mathbb{D}{ }^{1}{ }^{1}$ Yanyan Li $\mathbb{D}{ }^{1}$, and Rui Zhang $\mathbb{D D}^{2,3}$ \\ ${ }^{1}$ School of Mechanical Engineering, Sichuan University, Chengdu 610065, China \\ ${ }^{2}$ State Key Laboratory of Gas Disaster Monitoring and Emergency Technology, Chongqing 400037, China \\ ${ }^{3}$ China Coal Technology and Engineering Group Chongqing Research Institute, Chongqing 400039, China \\ Correspondence should be addressed to Demin Chen; chendemin@stu.scu.edu.cn and Yanyan Li; yyl_scu@yeah.net
}

Received 8 February 2021; Revised 30 March 2021; Accepted 8 April 2021; Published 20 April 2021

Academic Editor: Jia Lin

Copyright (C) 2021 Demin Chen et al. This is an open access article distributed under the Creative Commons Attribution License, which permits unrestricted use, distribution, and reproduction in any medium, provided the original work is properly cited.

\begin{abstract}
The gas loss in sampling is the root of coalbed gas content measurement error. The pressure and particle size have a significant impact on the gas loss. Using the self-developed coal particle pneumatic pipeline transportation experimental system, this study investigated the pressure and particle size changes in the sampling pipeline. It is found that the sampling process can be divided into four stages: no flow field stage, sample outburst stage, stable conveying stage, and tail purging stage. The extreme pressure in the sampling pipeline appears at the sample outburst stage; and the pressure in the pipeline has levelled off after sharp decrease in the stable conveying stage. It is also found that the extreme pressure increases first and then decreases with the increase of particle size. The duration of outburst stage is negatively correlated with particle size, and that of stable conveying stage is positively correlated with particle size. In addition, the results show that the loss rate of 1-3 mm particles is the smallest after the test but that particles less than $1 \mathrm{~mm}$ increase by about two times and particles greater than $3 \mathrm{~mm}$ decrease by more than three times. The study also shows that the particle size distribution of coal samples is a single peak with left skew distribution, and the gas reverse circulation sampling test does not change the location of the peak but makes it higher and sharper. The single size coal sample is more likely to collide than the mixture. This study can help to advance the understanding of impact factors on gas loss during reverse circulation sampling.
\end{abstract}

\section{Introduction}

Gas content has been recognized as the basic parameter of gas disaster prevention as well as coalbed methane resource development and applications [1-3]. Accurate measurement of gas content has considerable practical value and significance for productivity evaluation of coalbed methane. Regarding the accurate measurement of gas content in the coal seam, the direct methods for measurement of gas content based on air reverse circulation sampling were invented by Chinese researchers [4]. These researchers achieved stable measurement of gas content in a wide range of holes of $80 \mathrm{~m}$ depth with a measurement time of less than $8 \mathrm{~h}$. However, the problem of large measurement error has not been resolved.

In direct methods for measurement of gas content, the gas desorption amount and residual gas content from a coal sample are firstly measured, and then the gas loss in the sampling process is assessed. The gas loss in the sampling process has been recognized as the error source of this method [5]. Much work has been done by experts and scholars on the calculation of gas loss in the sampling process. Furthermore, some calculation models, such as the Barrer [6-8] model, Winter [9] model, Bolt [10] model, and Airey [11] model, have been developed. This gradually led to the development of a method to reverse the amount of gas loss in the sampling process by using these calculation models. However, these methods are based on the condition of fixed particle size and pressure and do not consider the influence of pressure and particle size change on gas loss during sampling.

In the process of sampling, the gas loss comes from the gas desorption and diffusion of granular coal. Gas 
desorption of granular coal is the gas transfer process in porous media, and this process is affected by particle size, pressure, temperature, and other factors $[12,13]$. Wang et al. [14] showed that the sensitivity of gas desorption law to particle size, temperature, pressure, moisture content, and forming pressure was pressure $>$ temperature $>$ particle size $>$ moisture content $>$ forming pressure. Qin et al. [15] proved that the desorption process of granular coal was inhibited when the desorption environment pressure was higher than the atmospheric pressure. Chen et al. [16] found that the negative pressure desorption environment significantly promoted gas desorption.

The influence of particle size on gas loss is reflected in the influence of particle size on desorption speed. The larger the particle size of the coal sample, the smaller the initial kinetic diffusion parameter, and the smaller the amount of gas desorption at the same time $[17,18]$. On the other hand, the gas desorption behaviors of coal sample correlate with the surface area and depend significantly on porosity [19]. Meanwhile the coal sample with a smaller particle size has a higher specific surface area and higher pore volume [20, 21]. The specific surface area and larger pore volume can reduce the resistance of gas desorption inside the coal sample, thus increasing the gas desorption at a given time [22]. From the results of these studies, it is evident that pressure and particle size have great influence on gas desorption of coal samples. This means that the pressure and particle size have a close relation with the gas loss in the sampling process. Therefore, when calculating the amount of gas loss in the process of sampling, we need to pay attention to the changing law of pressure and particle size.

The air reverse circulation sampling technology is a method that brings the coal sample at the bottom of the hole to the surface from the central channel of the drill pipe with the help of compressed air [23]. It is currently the most commonly used sampling method in coal seam gas content measurement. The research on this sampling technology mainly focuses on the characteristics of the gas-solid flow field in the reverse circulation pipeline [23-26] and the improvement of sampling efficiency [27-29]. However, there is a lack of studies on the change rule of factors affecting gas loss in the process of sampling.

This study mainly discussed the factors affecting the gas loss during sampling rather than desorption behaviors in a closed space. Therefore, the temperature, moisture content, forming pressure, and other factors were not investigated. Instead, the change rules of pressure and particle size were experimentally studied, aiming to reveal the change rules of pressure and particle size during reverse circulation sampling and provide the basic theory for the establishment of a more accurate gas loss compensation model.

\section{Materials and Methods}

2.1. Experimental Setup. To study the change rules of pressure and particle size in the process of sampling, an experimental reverse circulation sampling device was designed. The experimental system included air compressor, pressure gauge, gas flowmeter, hopper, conveying pipeline, and high-precision pressure sensors. The experimental system is shown in Figure 1.

The parameters of the main parts are outlined as follows:

(1) Air compressor: maximum power of $110 \mathrm{Kw}$, exhaust volume of $17.1 \mathrm{~m}^{3} / \mathrm{min}$, and exhaust pressure of 1.0 MPa.

(2) Detecting system: a pressure gauge with range of $0-1.6 \mathrm{MPa}$ was used to monitor the output pressure of the air compressor. The flowmeter was used to monitor the instantaneous flow and velocity in the pipeline. In addition, eight pressure sensors were arranged on the pipeline. The pressure sensors were installed at $0.1 \mathrm{~m}, 4 \mathrm{~m}, 8 \mathrm{~m}, 12 \mathrm{~m}, 16 \mathrm{~m}, 24 \mathrm{~m}, 65 \mathrm{~m}$, and $80 \mathrm{~m}$ from the feed port. The sampling frequency of the pressure sensor was 2400 times in $1 \mathrm{~s}$, and the accuracy level was 0.5 . In addition, the concentrator and software were designed for storing measurement data.

(3) Coal sample conveying system: the design volume of the bunker was $15 \mathrm{~L}$, which can hold a coal sample of about $12 \mathrm{~kg}$. The inner diameter of the pipeline was $40 \mathrm{~mm}$, which was consistent with the inner diameter of the double-barreled drilling rod used in the current air counter circulation method. The total design length of the pipeline was $80 \mathrm{~m}$, and a mesh bag was used to collect coal samples.

(4) Granularity analysis system: the OCCHIO ZEPHYR ESR2 particle analyzer was used to determine the particle distribution of coal samples before and after the air reverse sampling test. This allowed easy and rapid analysis of the particle size parameters, shape parameters, and number of particles in the range of $30 \mu \mathrm{m}-30 \mathrm{~mm}$.

2.2. Sample Preparation. The coal samples used in this experiment were collected from No. 4 coal Seam of Xintian Colliery, which is located in Qianxi County of Guizhou Province. The location of the mine is shown in Figure 2.

The process of sample preparation is shown in Figure 3. The preparation process of coal sample was as follows. First, the cone bit and PDC (Polycrystalline Diamond Compact) bit were used to drill with the parameters of reverse circulation sampling to collect the original coal sample. With the aid of the particle analyzer, the particle size distribution of the original coal sample was measured. Moreover, the $f$ value (consistent coefficient of coal) of the coal sample was measured in accordance with industry standards. Subsequently, the pulverizer was used to crush the lump coal of No. 4 coal seam of Xintian Colliery, and the powdered coal with various sizes was obtained after screening. Finally, according to the particle size distribution of the original coal sample, the test coal sample was obtained by mixing the powdered coal.

According to the coal sample size commonly used in gas content measurement, the original coal sample size was classified as $\leq 1 \mathrm{~mm}, 1-3 \mathrm{~mm}, 3-4 \mathrm{~mm}, 4-5 \mathrm{~mm}, 5-6 \mathrm{~mm}$, 6-7 $\mathrm{mm}$, and $7-8 \mathrm{~mm}$. The particle size distribution of the 


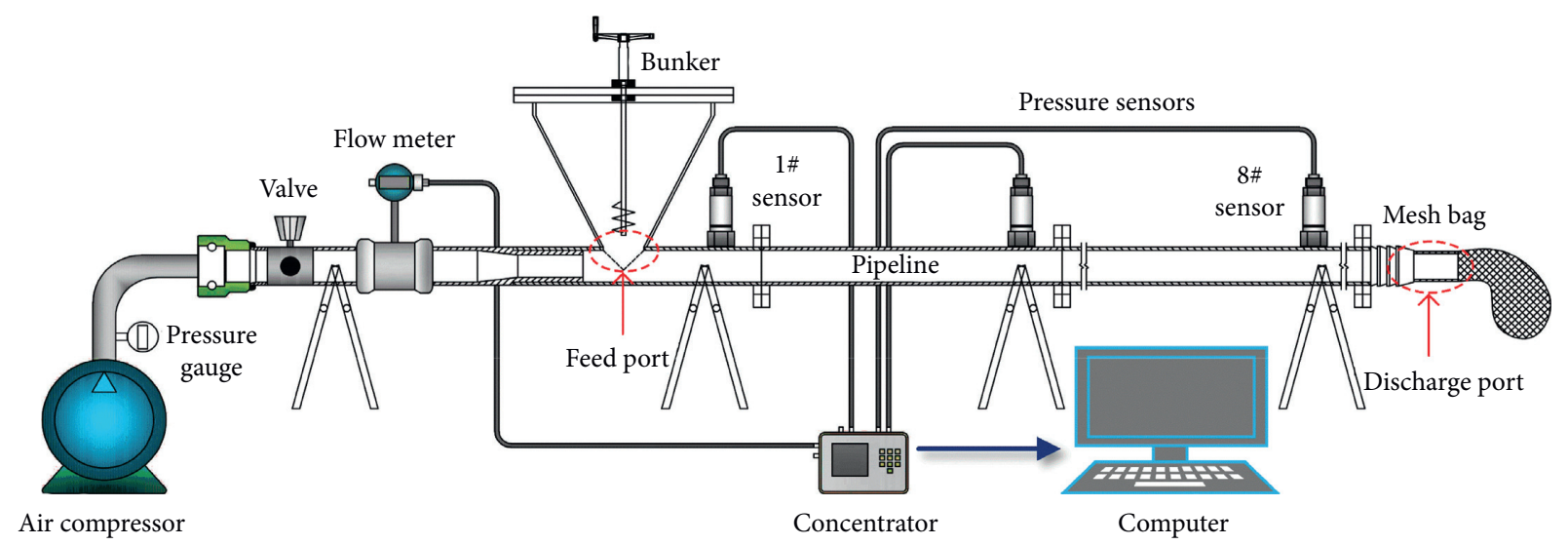

(a)
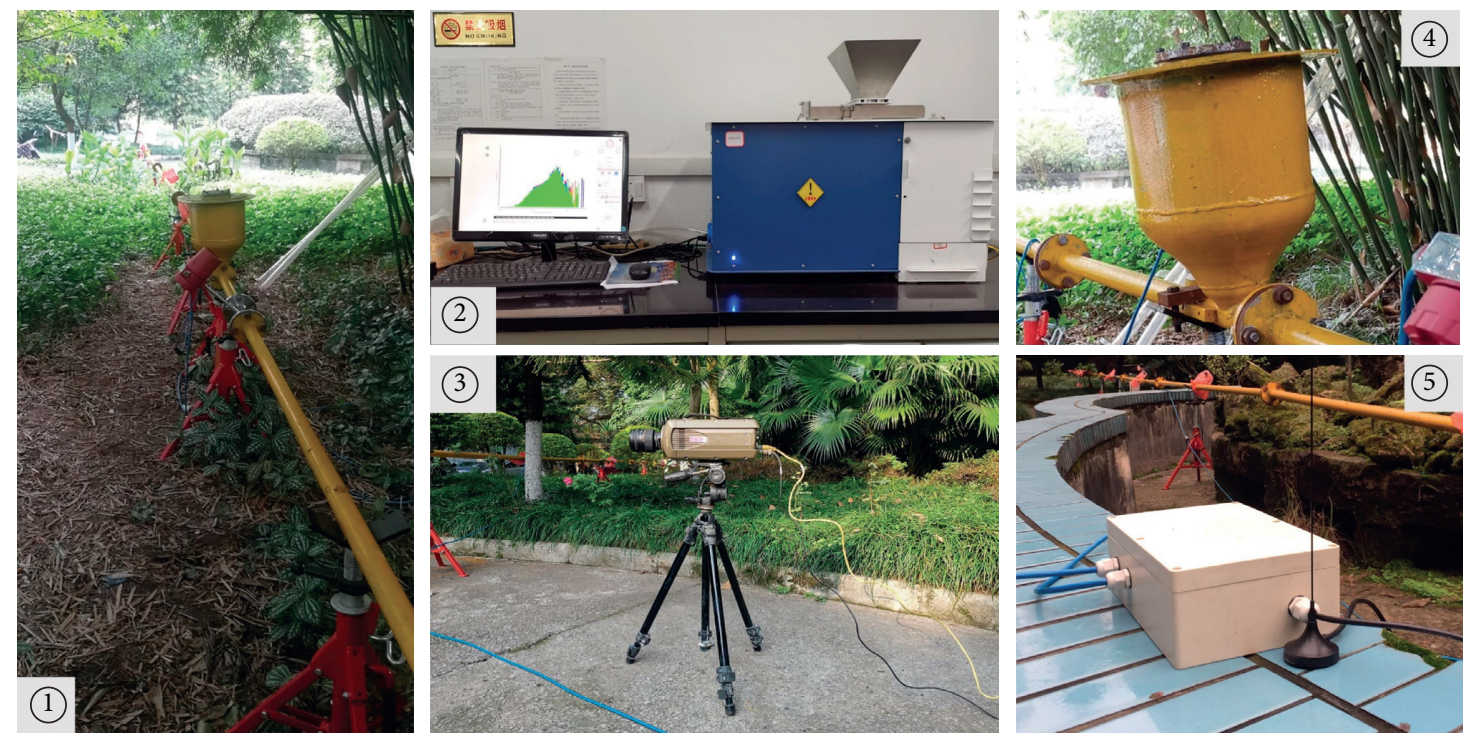

(b)

FIgURE 1: The experimental system. (a) Schematic diagram of the experimental system. (b) Physical map of the experimental system: (1) Conveying pipeline. (2) Particle analyzer. (3) High-speed camera. (4) Bunker. (5) Concentrator.

original coal sample drilled by using the cone bit and PDC bit is shown in Table 1. According to Table 1, two groups of coal samples were configured for each particle size distribution, four groups in total, of which two groups corresponding to the cone bit were numbered $1 \#$ and $2 \#$, and two groups corresponding to the PDC bit were numbered 3 \# and 4 \#. The weights of $1 \#, 2$ \#, 3 , and 4 \# coal samples were $12 \mathrm{~kg}$. In addition, $8 \mathrm{~kg}$ coal samples were taken from 1-3 mm, 3-4 mm, 4-5 mm, 5-6 mm, 6-7 mm, and $7-8 \mathrm{~mm}$ as single particle size coal samples. The $f$ value of No. 4 coal seam of Xintian Colliery was 0.8 .

2.3. Experimental Procedure. After the equipment and the coal sample were prepared, the numbered coal samples were successively loaded into the bunker. Then, the air compressor was started. When the output pressure of the air pressure was stable at $0.6 \mathrm{MPa}$, the valve was opened. This allowed the compressed air to draw the coal sample into the pipeline and start transmission. At the same time, the sensors collected the pressure data in the transmission pipeline. When all the coal samples had been transported, the air compressor was turned off and the coal samples in sampling mesh bag were collected. Finally, the size distributions of coal samples collected were tested by particle analyzer.

\section{Results and Discussion}

\subsection{Pressure Variation during the Process of Sampling}

3.1.1. Pressure Characteristics in the Pipe during Mixed Coal Sample Tests. The pressure change in the air reverse circulation sampling pipeline is the result of the kinetic energy transfer between gas and particles, as well as the conversion of the gas phase kinetic energy and pressure potential energy. Pressure variation in the pipeline during the tests of the mixture sample is shown in Figure 4.

The whole test process can be divided into four stages: no flow stage, sample outburst stage, stable conveying stage, and 


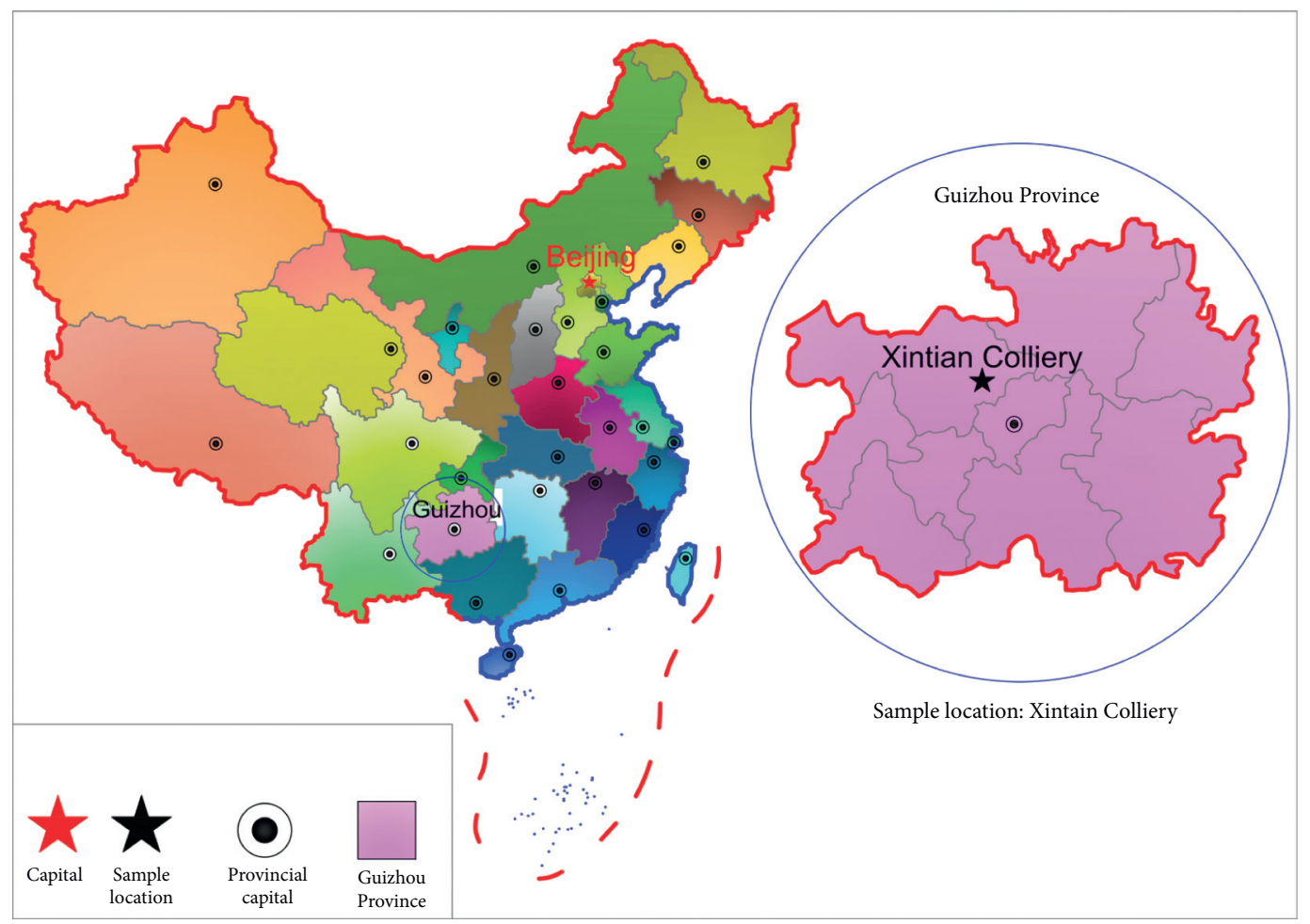

FIgURE 2: Geographical location of the coal sample.

tail purging stage. The no flow stage refers to the stage from energizing the detecting system to opening the valve. At this stage, there is no fluid in the pipeline, so the indication of the sensor is zero. The sample outburst stage refers to the completion of transportation of coal sample accumulated at the feed port. In the sample outburst stage, most of the pressure potential energy of the compressed air was rapidly converted into kinetic energy, and part of the kinetic energy was transferred to the coal sample at the feed port, so that the coal sample could achieve acceleration and move with the compressed air. Currently, the moving speed of the coal sample was less than that of the compressed air. Therefore, the movement of compressed air is the main element in the pipeline, and the pressure in the pipeline increases from atmospheric pressure to compressed air pressure. It can be seen from Figure 4 that the extreme pressure appears at the sample outburst stage. The extreme pressures of 1 \# sensor were $558.84 \mathrm{~Pa}, 508.04 \mathrm{~Pa}, 509.85 \mathrm{~Pa}$, and $514.30 \mathrm{~Pa}$, and the maximum pressures of 8 \# sensor were $76.44 \mathrm{~Pa}, 60.29 \mathrm{~Pa}$, $75.14 \mathrm{~Pa}$, and $78.31 \mathrm{~Pa}$, respectively. This illustrates that the closer to the feed port, the higher the extreme pressure, and the closer to the discharge port, the smaller the extreme pressure. The distinction between the abscissa of point "e" and point " $f$ " in Figure 4 represents the time difference when the extreme pressure reaches 1 \# sensor and 8 \# sensor and also represents the duration of sample outburst stage. The durations of sample outburst stage in the test of 1 \#, 2 , 3 \#, and 4 \# coal samples were $1.8 \mathrm{~s}, 0.8 \mathrm{~s}, 1.2 \mathrm{~s}$, and $1.0 \mathrm{~s}$, respectively.

In the stable conveying stage, coal sample enters the pipeline evenly from the feed port. The kinetic energy and pressure potential energy of the compressed air were converted into a dynamic equilibrium. Therefore, there was relatively little pressure change in the pipeline, which is reflected in that the curve of the stable conveying stage tends to be stable after a sharp drop in Figure 4 . The durations of stable conveying stage in the test of 1 \#, 2 \#, 3 \#, and 4 \# coal samples were $85.4 \mathrm{~s}, 86.2 \mathrm{~s}, 85.2 \mathrm{~s}$, and $80.4 \mathrm{~s}$, respectively.

In the tail purging stage, the coal sample is no longer supplied to the pipeline from the feed port, so the remaining coal sample in the pipeline is reduced. Therefore, the movement resistance of compressed air is reduced, and more pressure potential energy is converted into kinetic energy, resulting in the reduction of static pressure in the pipeline. When the particles are completely transported, the flow field returns to pure air flow, and the pressure in the pipeline returns to a lower level. It is shown in Figure 4 that the curve of the purge stage tends to be stable after the obvious decrease.

The pressure values of each measuring point in the pipeline at 35 s, 55 s, 75 s, and 95 s are shown in Figure 5. It can be seen that, in the stable conveying stage, the pressure variation trends of all measurement points are basically the same. The further from the feed port, the lower the static pressure. At the same time, the pressure loss values of the same distance are almost equal. The pressure difference between each measuring point at $35 \mathrm{~s}$ and $55 \mathrm{~s}$ is significantly higher than that at $55 \mathrm{~s}$ and $75 \mathrm{~s}$. This means that the closer to the sample outburst stage, the higher the static pressure loss value, and much of the lost pressure potential energy is converted into the kinetic energy of compressed air and coal particles. Therefore, the moving speed of particles is still on 


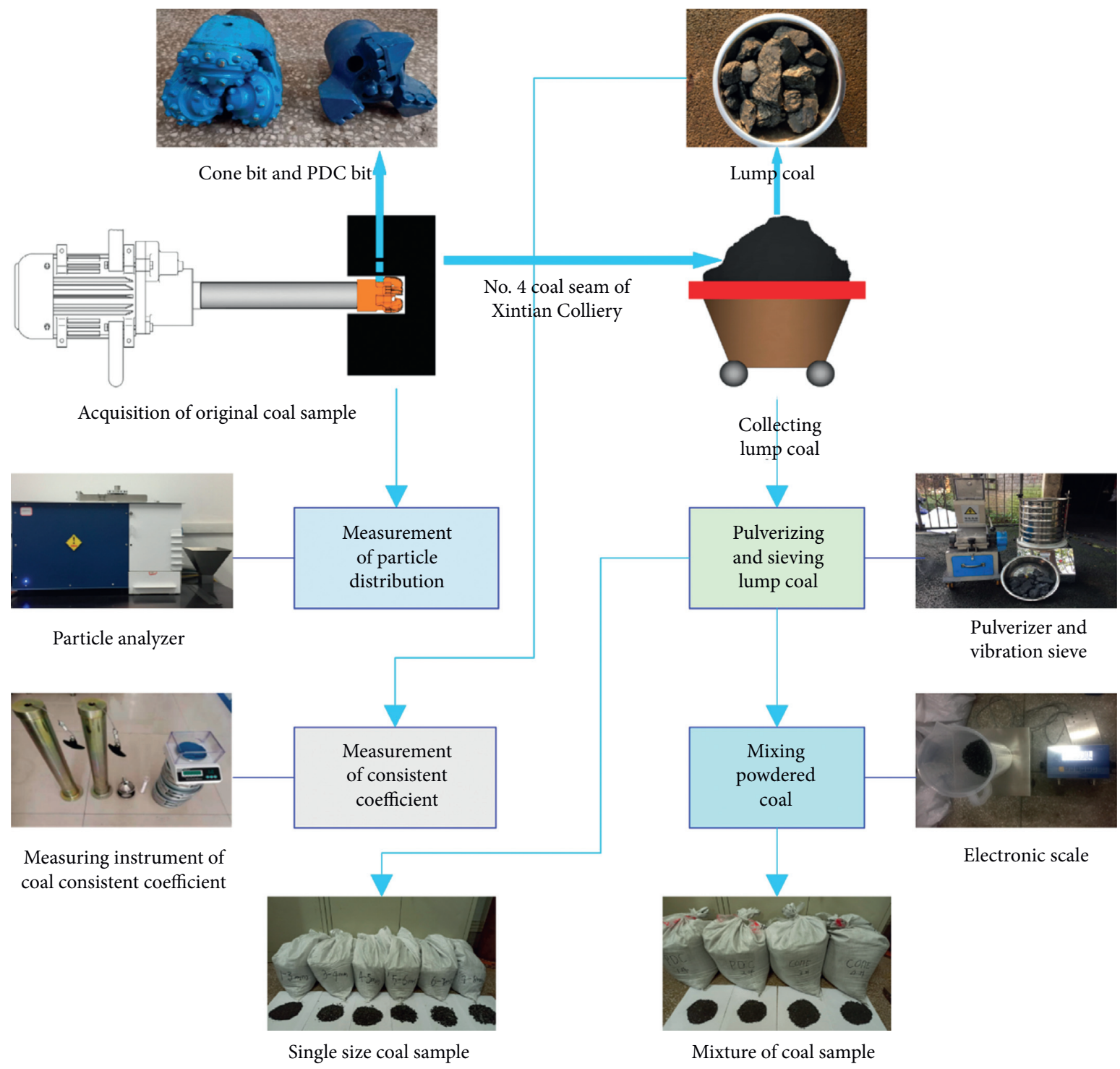

FIGURE 3: The process of coal sample preparation.

TABle 1: Particle size distribution of the original coal sample.

\begin{tabular}{lccccccc}
\hline Sample size & $\leq 1 \mathrm{~mm}$ & $1-3 \mathrm{~mm}$ & $3-4 \mathrm{~mm}$ & $4-5 \mathrm{~mm}$ & $5-6 \mathrm{~mm}$ & $6-7 \mathrm{~mm}$ & $7-8 \mathrm{~mm}$ \\
\hline Cone bit & 34.61 & 35.10 & 8.27 & $9.10 \%$ & $4.51 \%$ & $5.45 \%$ & $2.96 \%$ \\
PDC bit & 30.87 & 43.29 & 10.10 & $5.61 \%$ & $5.32 \%$ & $1.25 \%$ & $3.56 \%$ \\
\hline
\end{tabular}

the rise, which increases the time during which the coal sample remains in the pipeline and increases the gas loss of the coal sample.

\subsubsection{Effect of Particle Size on the Pressure Characteristics in} the Sampling Pipeline. Pressure variation in the pipeline during the tests of single size coal sample is shown in Figure 6. The relationship between the pressure characteristics and the particle size is shown in Figure 7. Two laws can be drawn from Figures 6 and 7: One is that the duration of outburst stage is negatively correlated with particle size, and that of stable conveying stage is positively correlated with particle size. The other is that the extreme pressure increases first and then decreases with the increase of particle size.

In the test of 1-3 mm coal sample, the duration of sample outburst stage is $2.4 \mathrm{~s}$, and that of the stable conveying stage is $20.6 \mathrm{~s}$. Meanwhile, in the test of $7-8 \mathrm{~mm}$ coal sample, the duration of sample outburst stage is $0.8 \mathrm{~s}$, which is only onethird of the $1-3 \mathrm{~mm}$ coal sample. The duration of stable conveying stage is $46.8 \mathrm{~s}$, which is increased by $127 \%$. This shows that the larger the coal sample size, the shorter the sample outburst stage, but the longer the duration of the stable conveying stage. In the test of $1-3 \mathrm{~mm}$ coal sample, the extreme pressures of 1 \# and 8 \# sensors are $520.53 \mathrm{~Pa}$ and 104.73 $\mathrm{Pa}$, respectively. In the test of $6-7 \mathrm{~mm}$ coal sample, 

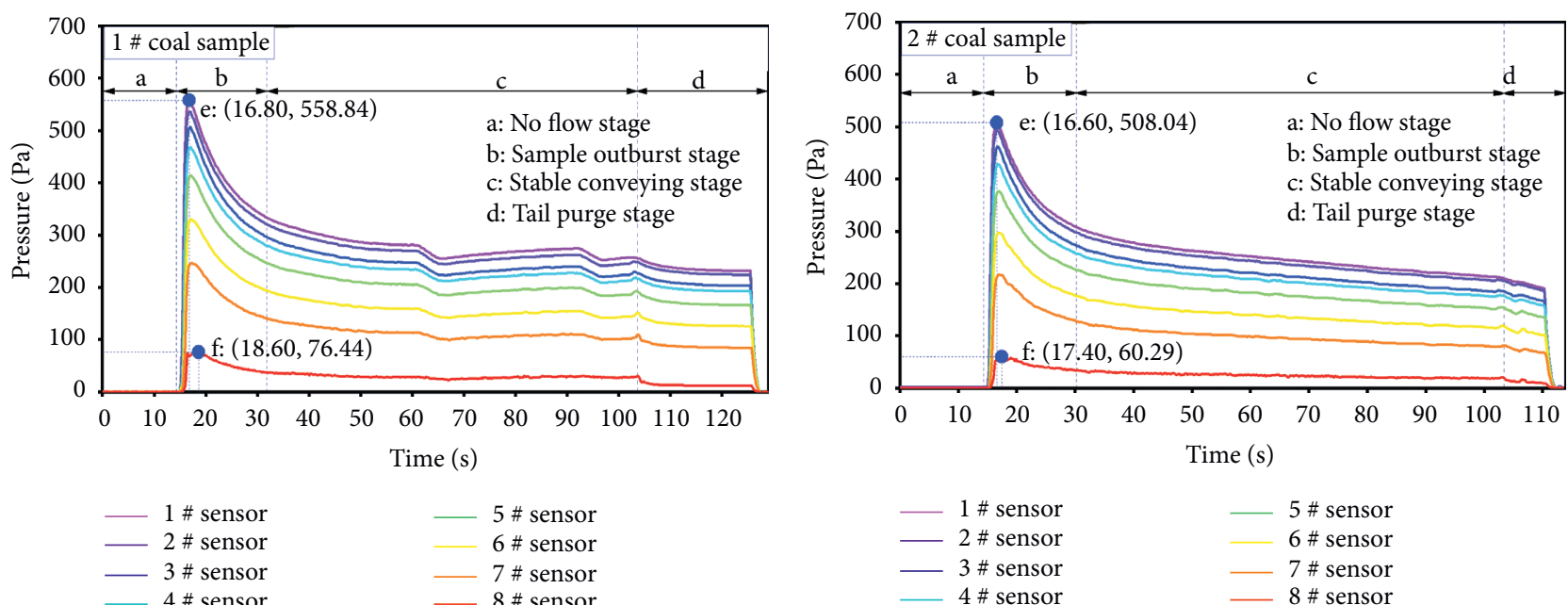

(a)

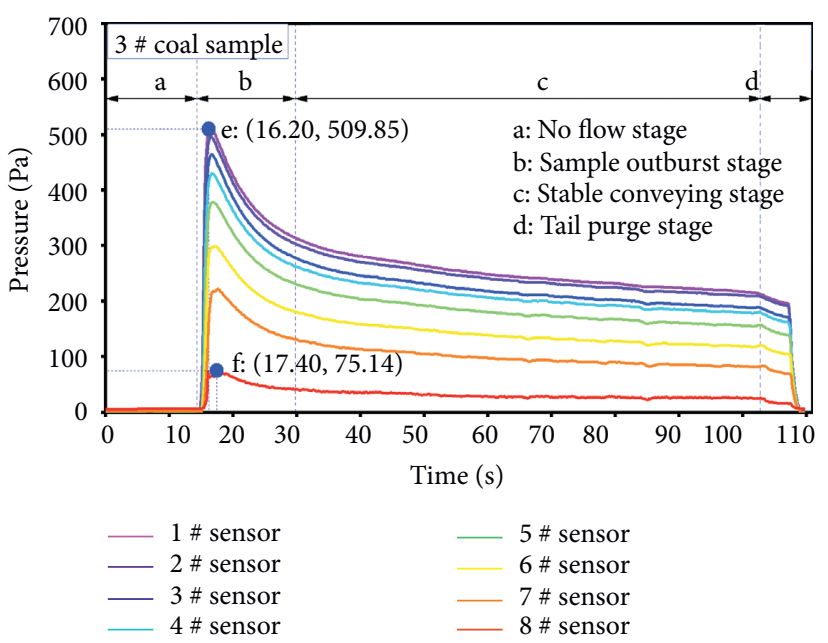

(c)

(b)

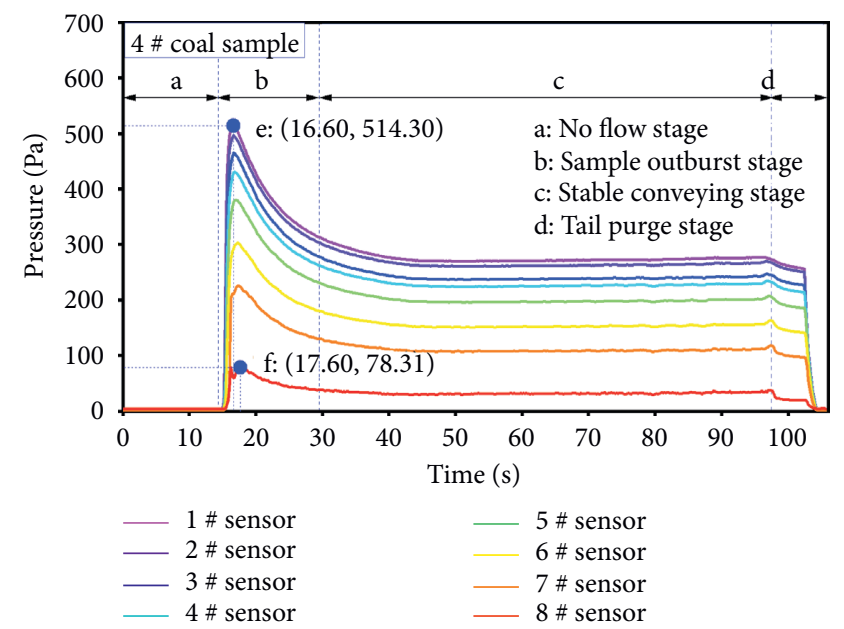

(d)

Figure 4: Pressure variation in the pipeline during the tests of the mixture sample. Point "e" represents the extreme pressure point of 1 \# sensor, and point "f" represents the extreme pressure point of 8 \# sensor.

the extreme pressures of 1 \# and 8 \# sensors are $520.53 \mathrm{~Pa}$ and $104.73 \mathrm{~Pa}$, which increased by $6.4 \%$ and $13.0 \%$, respectively. However, the extreme pressures of 1 \# and 8 \# sensors during the test of 7-8 mm coal sample are $547.78 \mathrm{~Pa}$ and $104.95 \mathrm{~Pa}$, respectively, which are $1.1 \%$ and $12.8 \%$ lower than those of the test of $6-7 \mathrm{~mm}$ coal sample.

Further analysis of the results showed that if the particle size is too small, the density of small particle size sample at the feed port will be uneven, which will lengthen the duration of sample outburst stage. On the other hand, the smaller the particle size, the larger the total surface area of coal sample with the same quality and the more contact area with compressed air. As a result, more pressure potential energy of compressed air will be converted into kinetic energy of coal sample. The extreme pressure of the sample outburst stage is reduced. The movement speed of coal sample is improved, and the duration of stable conveying stage is shortened.

\subsection{Particle Size Variation during the Process of Sampling}

3.2.1. Particle Size Variation of the Mixed Coal Sample The coal samples before and after the gas reverse circulation sampling tests were mixed evenly, and a certain amount of coal samples was taken from each coal sample twice. Then, the coal samples taken each time were divided into two parts: one for backup and the other for particle size distribution measurement using the particle analyzer. The particle size distribution (Feret's minimum diameter volume distribution) after the mixed coal sample tests is shown in Table 2.

By comparing the original particle size distribution (shown in Table 1) with the particle size distribution after the tests (shown in Table 2), 30\% of the original particle diameter is less than $1 \mathrm{~mm}$, while more than $60 \%$ of the coal samples had a diameter less than $1 \mathrm{~mm}$ after the test, which is double. In addition, more than $25 \%$ of the particles of the original coal samples are larger than $3 \mathrm{~mm}$, while only $7 \%$ of 


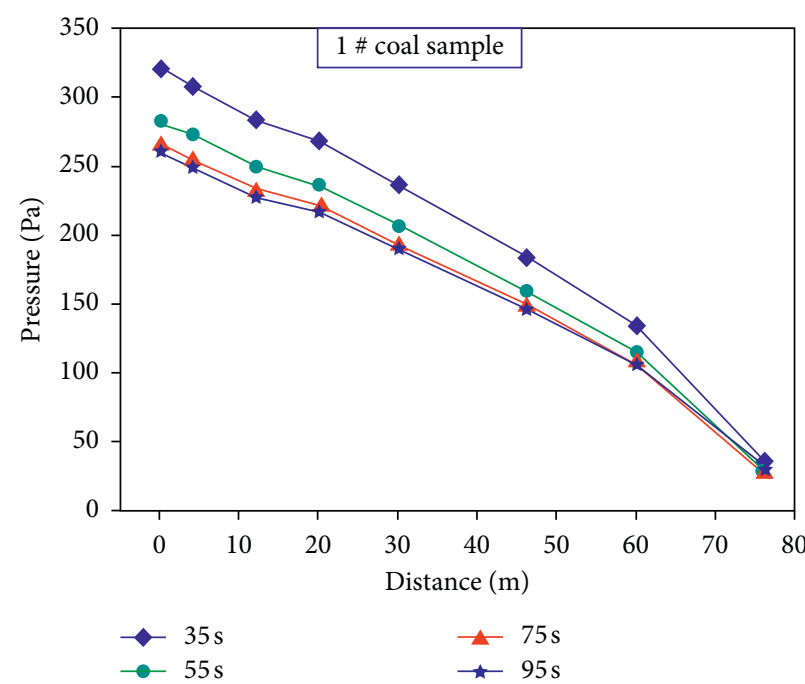

(a)

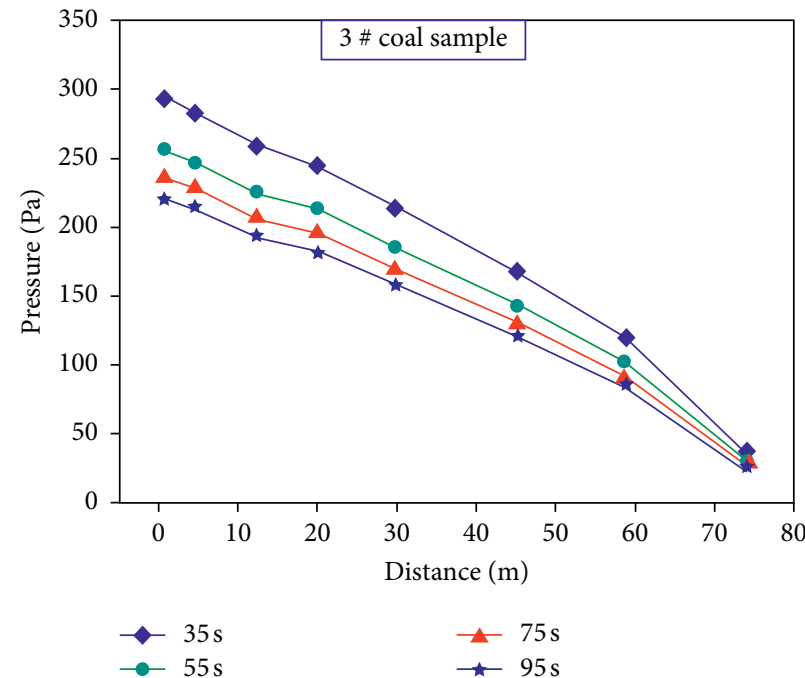

(c)

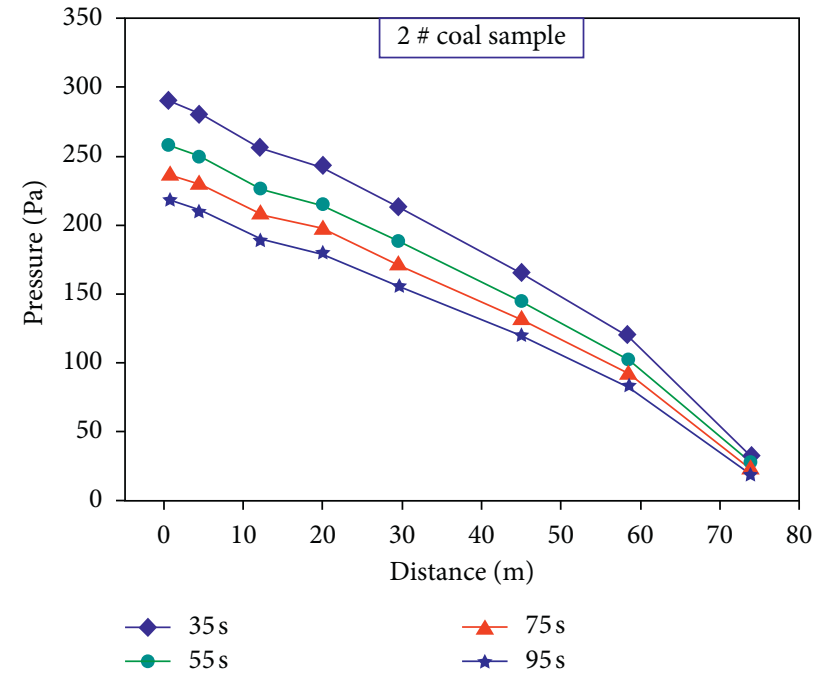

(b)

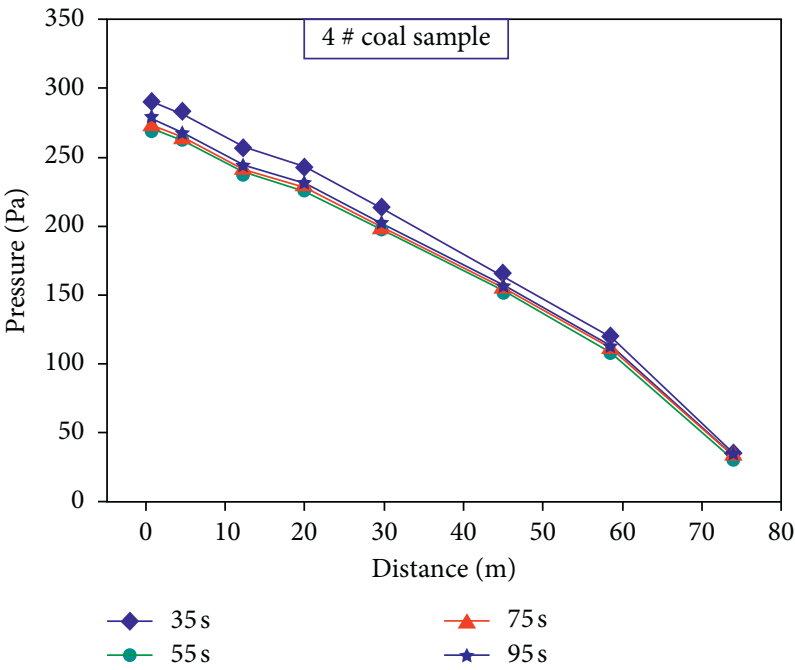

(d)

Figure 5: Pressure value in pipeline at different time of stable conveying stage.

the particles of the coal sample are larger than $3 \mathrm{~mm}$ after the test, almost 3.6 times less. This proved that the particle size changed significantly in the process of gas reverse circulation sampling due to particle-particle and particle-tube wall collision, which is mainly manifested in the sharp decrease in large particles and the obvious increase in small particles. Owing to the change in particle size, the total surface area of the coal sample increased, the gas desorption rate of the coal sample accelerated, and the gas loss increased.

According to Tables 1 and 2, coal sample particles larger than $3 \mathrm{~mm}$ account for a relatively small proportion. If those samples are selected to measure the gas content of coal seams, more coal samples will be obtained and more time will be spent on screening, resulting in a further increase in gas loss. Conversely, the gas loss of the coal sample particles less than $1 \mathrm{~mm}$ is serious. Therefore, it is suggested that a coal sample with $1-3 \mathrm{~mm}$ particles should be used in the actual measurement of gas content.
Figure 8 shows the distribution of particle size before and after the tests of mixed coal sample. Figure 9 shows the cumulative distribution of particle size before and after the tests of mixed coal sample. It is evident that the particle size distributions of coal samples before and after the tests are a single peak with left skew distribution. The gas reverse circulation sampling test does not change the location of the peak but makes the peak particle size distribution higher and sharper. The cumulative distribution of particle size before and after the test conforms to Rosin-Rammler distribution ( $\mathrm{R}-\mathrm{R}$ distribution) [30, 31], which is expressed as follows:

$$
F(d)=100-100 \exp \left[-\left(\frac{d}{d_{0}}\right)^{m}\right]
$$

where $F(d)$ is the cumulative distribution; $d$ is the particle diameter in $\mathrm{mm}$; $d_{0}$ is the median diameter in $\mathrm{mm}$, when $d_{0}=d, F(d)=63.2 \%$, and therefore $d_{0}$ is the particle size 


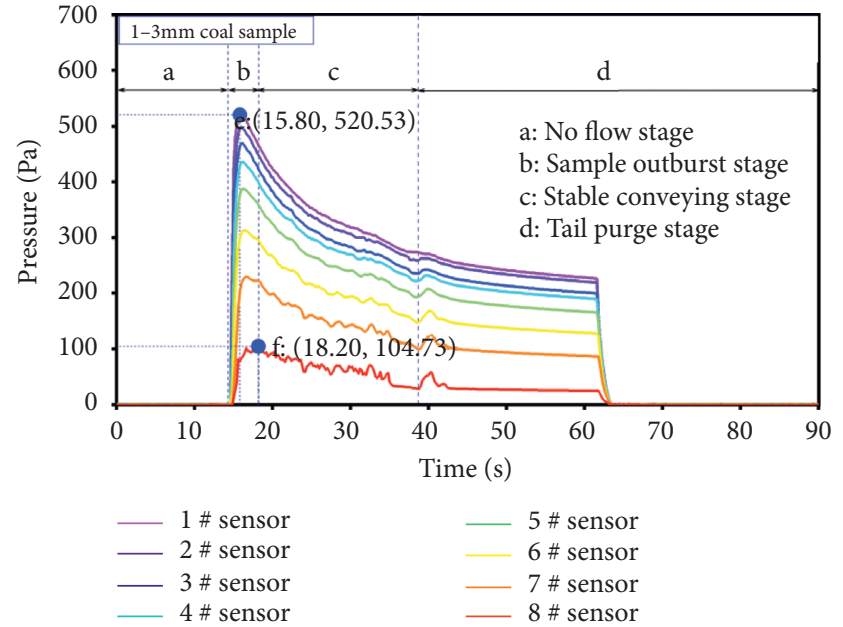

(a)

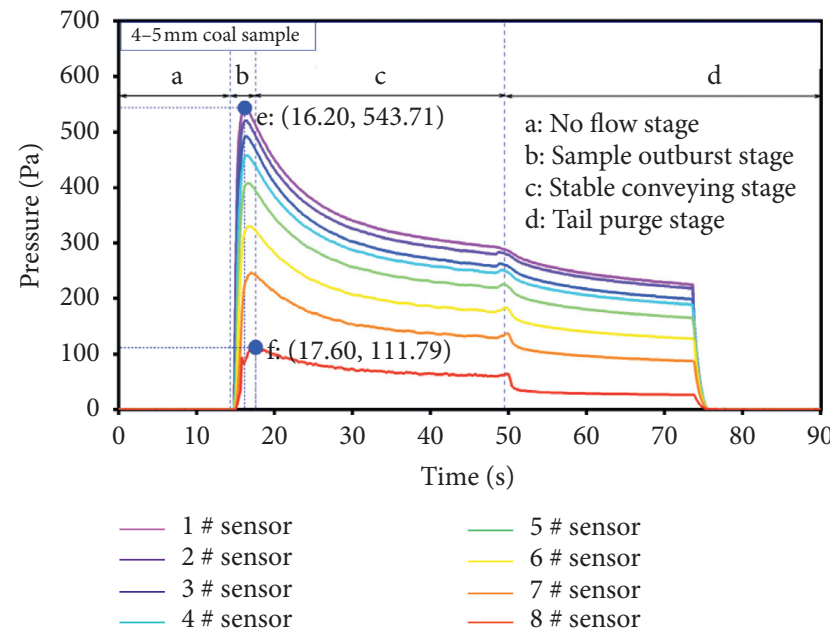

(c)

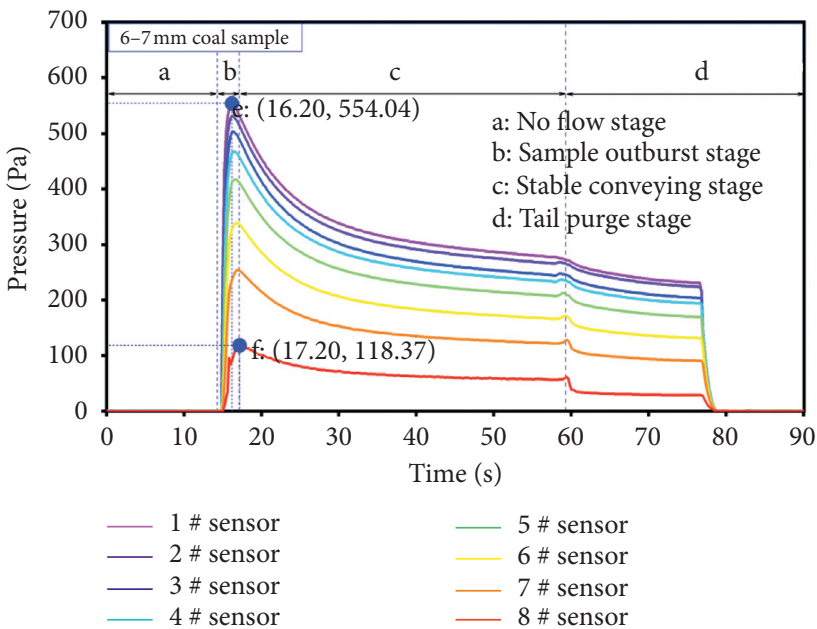

(e)

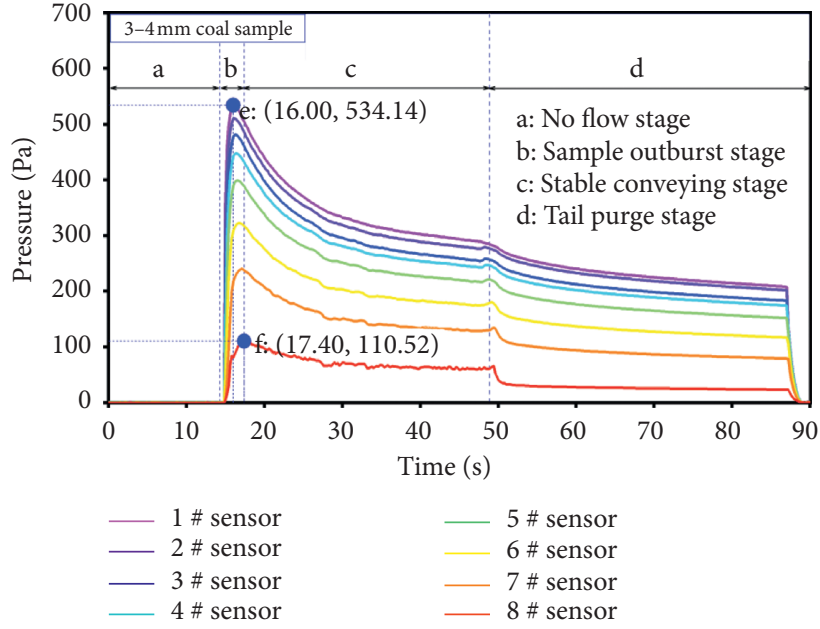

(b)

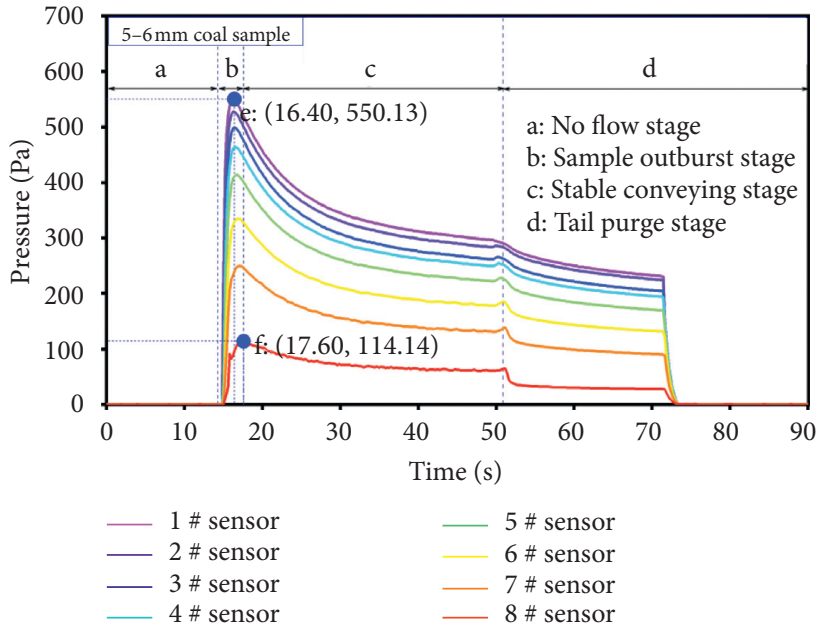

(d)

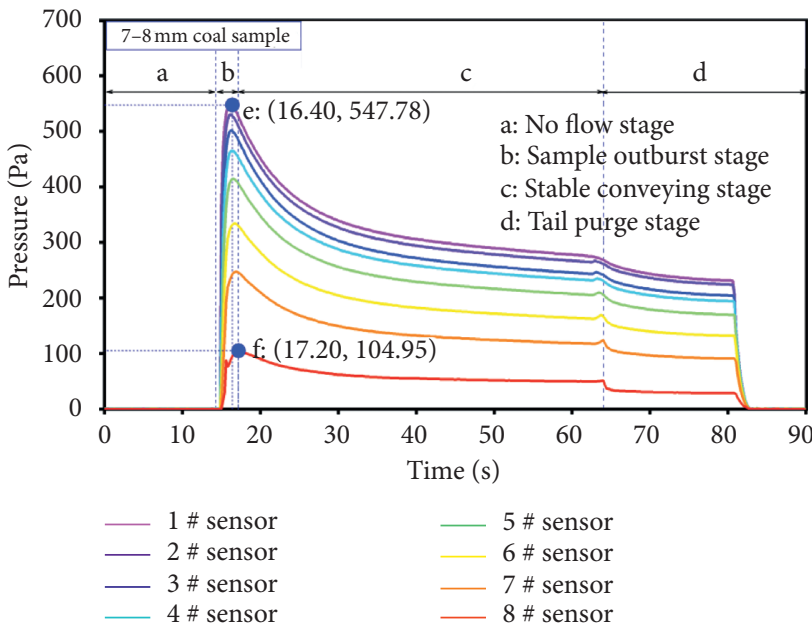

(f)

Figure 6: Pressure variation in the pipeline during the tests of single size coal sample. The point " $\mathrm{e}$ " represents the extreme pressure point of 1 \# sensor, and the point " $f$ " represents the extreme pressure point of 8 \# sensor. 


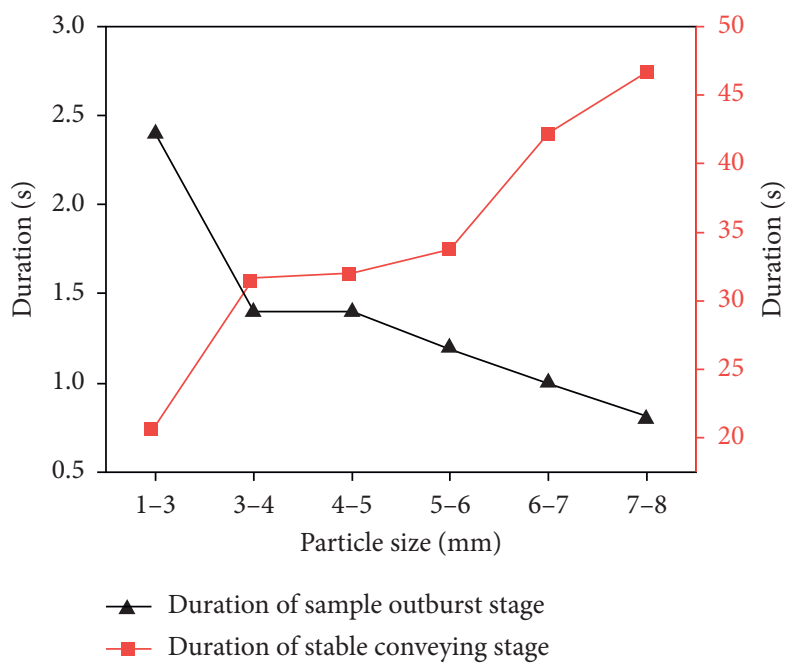

(a)

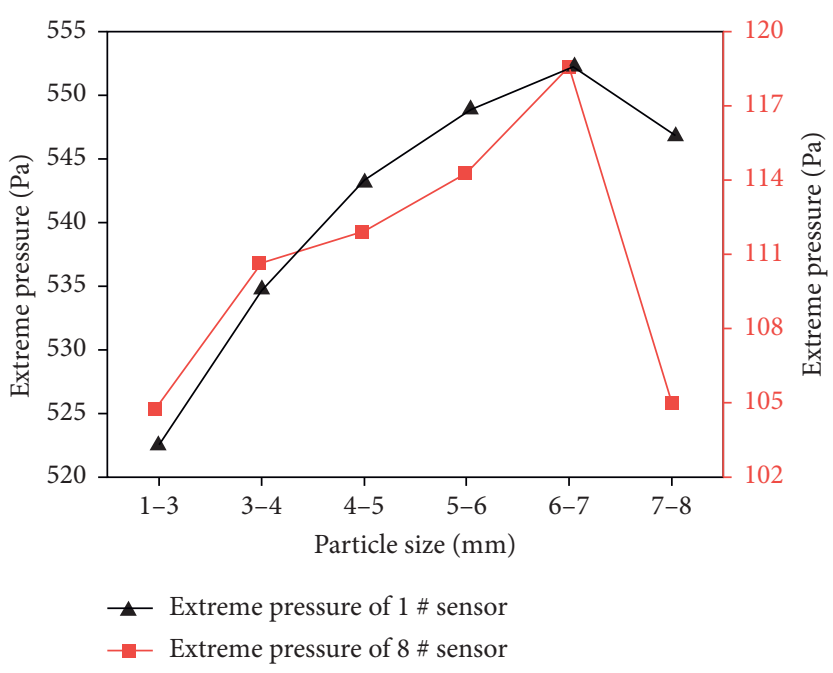

(b)

Figure 7: The relationship between the pressure characteristics and the particle size. (a) Duration of sample outburst stage and stable conveying stage. (b) Extreme pressure of 1 \# sensor and 8 \# sensor.

TABLe 2: Particle size distribution after the mixed coal sample tests.

\begin{tabular}{|c|c|c|c|c|c|c|c|}
\hline Sample size & $\leq 1 \mathrm{~mm}(\%)$ & $1-3 \mathrm{~mm}(\%)$ & 3-4 mm (\%) & $4-5 \mathrm{~mm}$ & $5-6 \mathrm{~mm}$ & 6-7 mm & $7-8 \mathrm{~mm}$ \\
\hline 1 \# coal sample & 62.32 & 32.54 & 2.06 & $1.83 \%$ & $1.24 \%$ & 0 & 0 \\
\hline 2 \# coal sample & 65.91 & 29.42 & 3.97 & $0.70 \%$ & 0 & 0 & 0 \\
\hline 3 \# coal sample & 64.74 & 29.41 & 3.61 & 0 & $2.24 \%$ & 0 & 0 \\
\hline 4 \# coal sample & 64.82 & 28.05 & 5.33 & $1.11 \%$ & $0.69 \%$ & 0 & 0 \\
\hline
\end{tabular}

corresponding to $F=0.632$; and $m$ is the parameter characterizing the particle size distribution range. After two logarithmic transformations of formula (1), the following result is obtained:

$$
\ln \left\{-\ln \left[\frac{1-F(d)}{100}\right]\right\}=m \ln d-m \ln d_{0} .
$$

A straight line can be obtained by plotting $\ln \{-\ln$ $[1-F(d) / 100]\}$ on $\ln d$. The slope of the line is the uniformity index $m$ of the R-R distribution equation, and then the characteristic particle size $d_{0}$ can be obtained according to the intercept of the line on the $Y$-axis. Take the derivative on both sides of formula (1) to obtain the particle size distribution density function:

$$
f(d)=F(d)^{\prime}=100 \frac{m}{d_{0}}\left(\frac{d}{d_{0}}\right)^{m-1} \exp \left[-\left(\frac{d}{d_{0}}\right)^{m}\right] .
$$

The percentage of particle volume between any two particle sizes can be calculated as follows:

$$
F\left(d_{2}\right)-F\left(d_{1}\right)=\int_{d_{1}}^{d_{2}} f(d) d(d)
$$

According to formula (2), linear regression was carried out for the cumulative particle size distribution data of the 1 \# coal sample after the test, as shown in Figure 10. The linear regression correlation coefficient $R^{2}=0.9971$ and the linear fitting degree is high. From the fitting results, it can be seen that the slope of the straight line is 0.95251 and the intercept is -6.53405 , and therefore the uniformity index of the R-R equation is $m=0.95251$ and the characteristic dimension is $d_{0}=0.9532 \mathrm{~mm}$. The same method was used to calculate the $\mathrm{R}-\mathrm{R}$ fitting characteristic parameters of each coal sample before and after the test, as shown in Table 3. Hereafter, according to formula (4) and the $m$ and $d_{0}$ values of each coal sample, it is easy to obtain the volume fraction of coal samples in any two particle size ranges.

As mentioned, $m$ is a parameter that characterizes the range of particle size distribution. The larger the value of $m$, the narrower the range of particle size distribution. On the contrary, the smaller the value of $m$, the larger the range of particle size distribution. Meanwhile, $d_{0}$ is also a parameter to describe the characteristics of particle size distribution. The larger value of $d_{0}$ indicates that the particle is inclined to the end with larger particle size. Conversely, it tends to the end with smaller particle size. Compared with the characteristic parameters of coal particle size distribution before the tests, the characteristic parameters of coal particle size distribution after the tests have little change in the $m$ value but the value of $d_{0}$ is generally reduced by more than two times. This reflects that, during the process of the air reverse circulation sampling test, the collision results in particle breakage, which makes the size of more than half of the coal sample particle less than $1 \mathrm{~mm}$. 


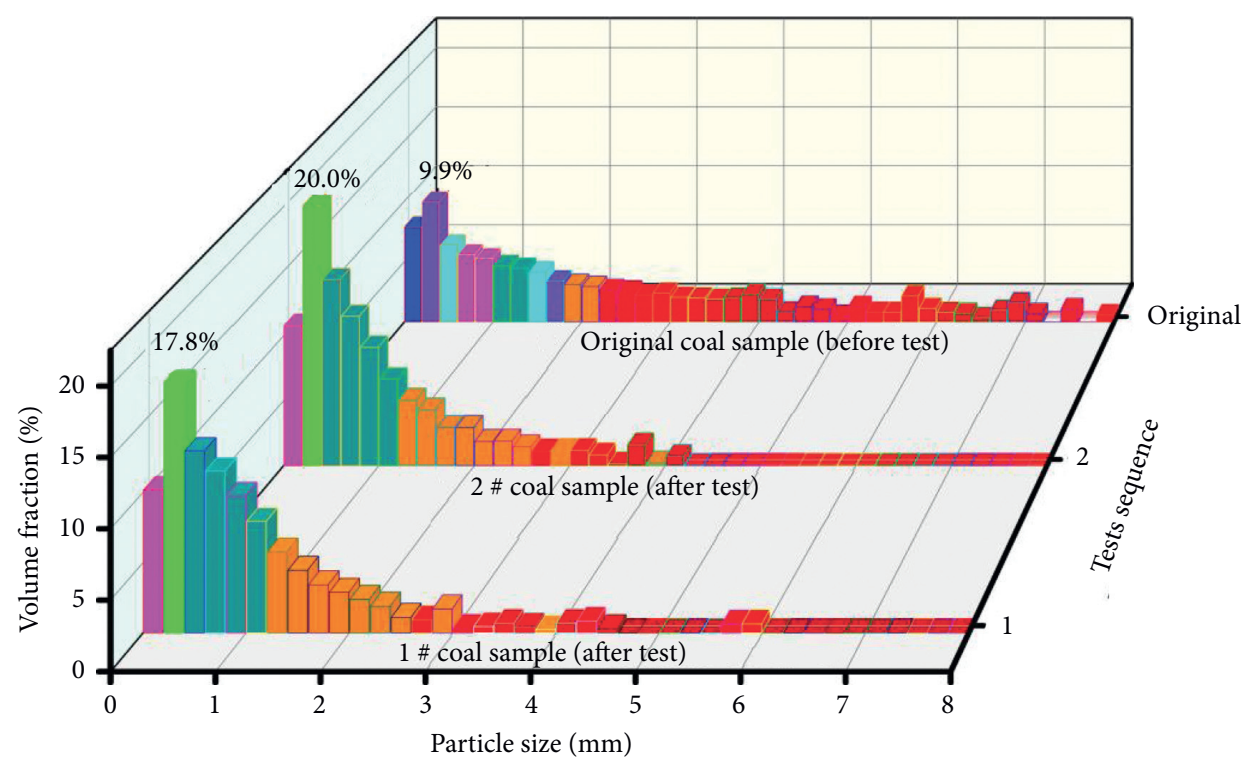

(a)

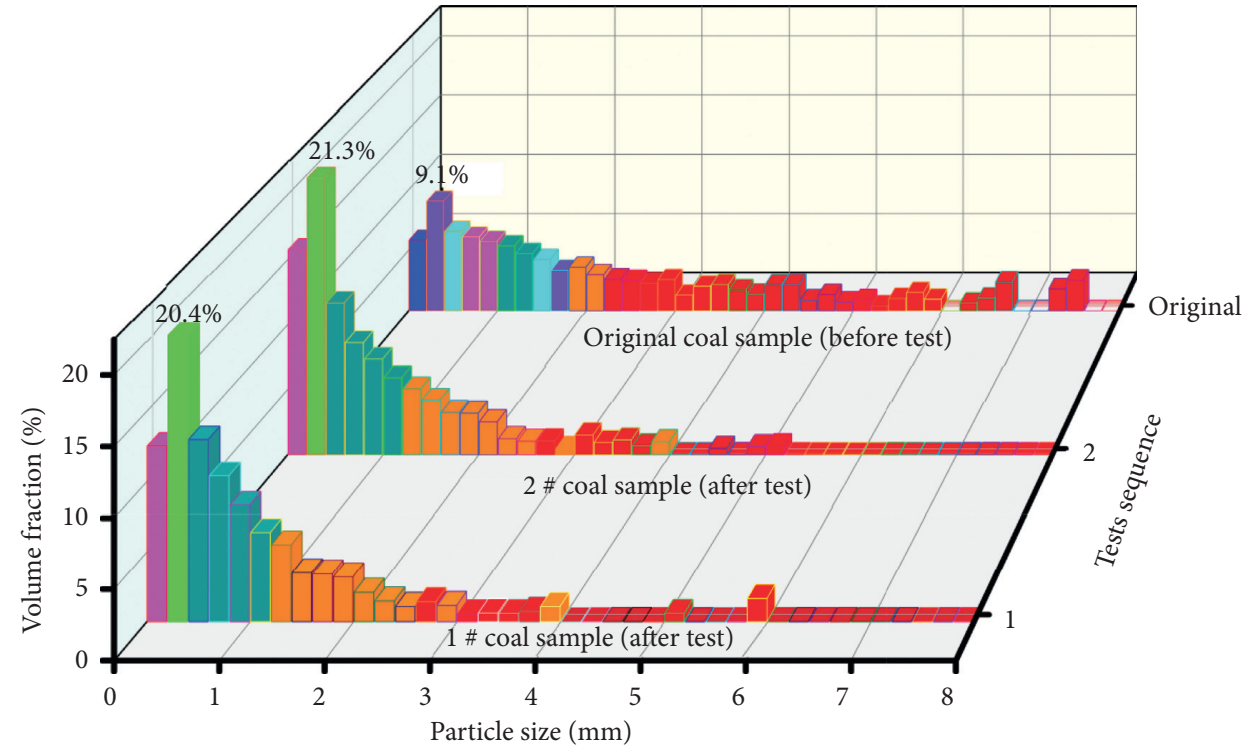

(b)

Figure 8: The histogram of particle size distribution before and after the tests. The volume fraction represents Feret's minimum diameter volume distribution. (a) 1 \# and 2 \# coal sample. (b) 3 \# and 4 \# coal sample.

3.2.2. Particle Size Variation of Single Size Coal Sample Using the same method as the mixed coal sample, the gas reverse circulation sampling tests with single particle size of 1-3 mm, 3-4 mm, 4-5 mm, 5-6 mm, 6-7 mm, and 7-8 mm were conducted. The distribution of particle size after the tests is shown in Figure 11, and the cumulative distribution of particle size after the tests is shown in Figure 12, and the $\mathrm{R}-\mathrm{R}$ fitting characteristic parameters of each single particle size coal sample are given in Table 4.

The results show that the particle size distribution after the test presents a single peak with left skewed distribution, and the cumulative distribution after the test conforms to the
$\mathrm{R}-\mathrm{R}$ distribution. However, there is no obvious correlation between the particle size distribution and the original particle size. The fitting parameters of cumulative distribution vary widely and are not correlated with the original particle size. When comparing the particle size distribution of the mixed coal sample and the single particle, it can be seen that the number of coal samples with a particle size greater than $3 \mathrm{~mm}$ after the single particle size test is lower. This indicates that the impact crushing of particles in the reverse circulation sampling pipeline is a random process and the impact crushing degree of uniform single size particles is more serious than that of mixed coal samples. 


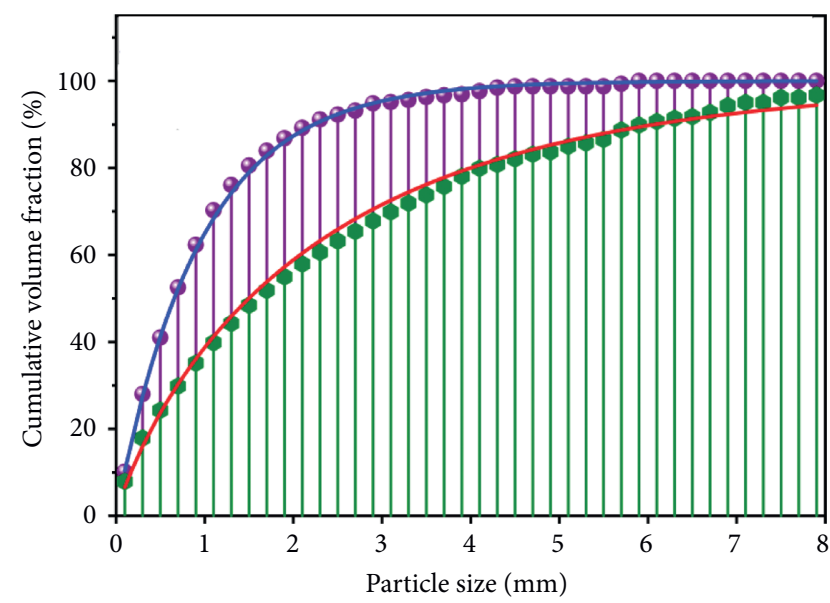

- After test

— $y=100-100^{*} \exp \left(-(x / 0.9533)^{\wedge} 0.9525\right.$

- Before test

$-y=100-100^{*} \exp \left(-(x / 2.2972)^{\wedge} 0.8577\right.$

(a)

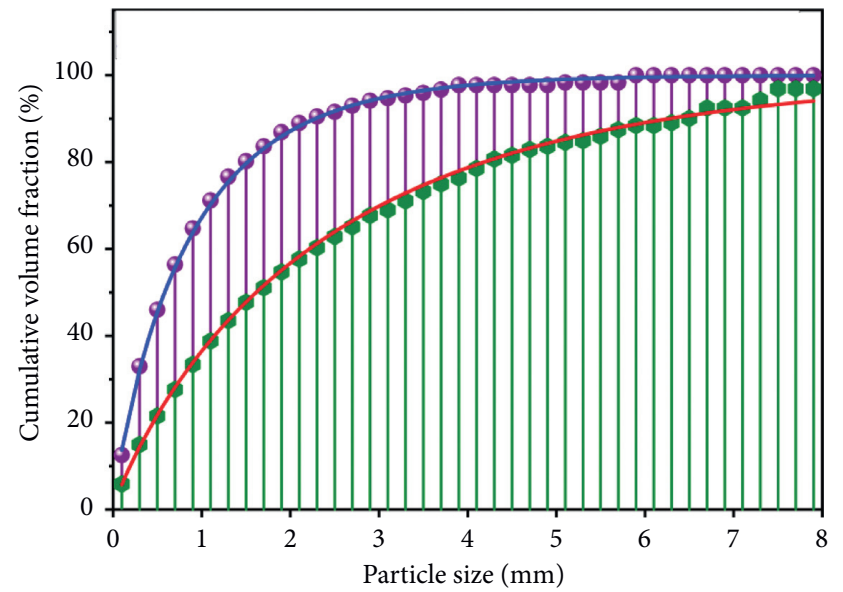

- After test

$-y=100-100^{*} \exp \left(-(x / 0.8835)^{\wedge} 0.8834\right.$

- Before test

$-y=100-100^{*} \exp \left(-(x / 2.4433)^{\wedge} 0.8994\right.$

(c)

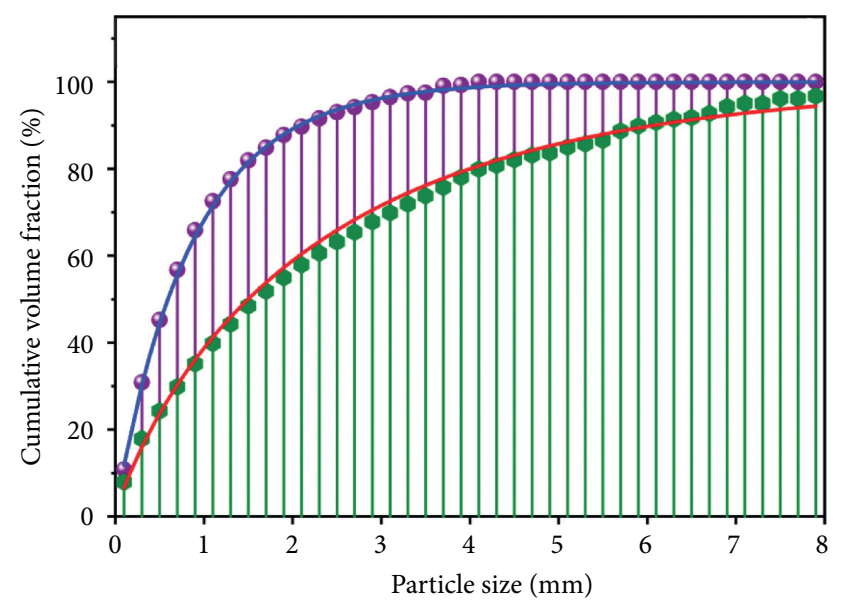

- After test

$-y=100-100^{*} \exp \left(-(x / 0.8695)^{\wedge} 0.9781\right.$

- Before test

$-y=100-100^{*} \exp \left(-(x / 2.2972)^{\wedge} 0.8577\right.$

(b)

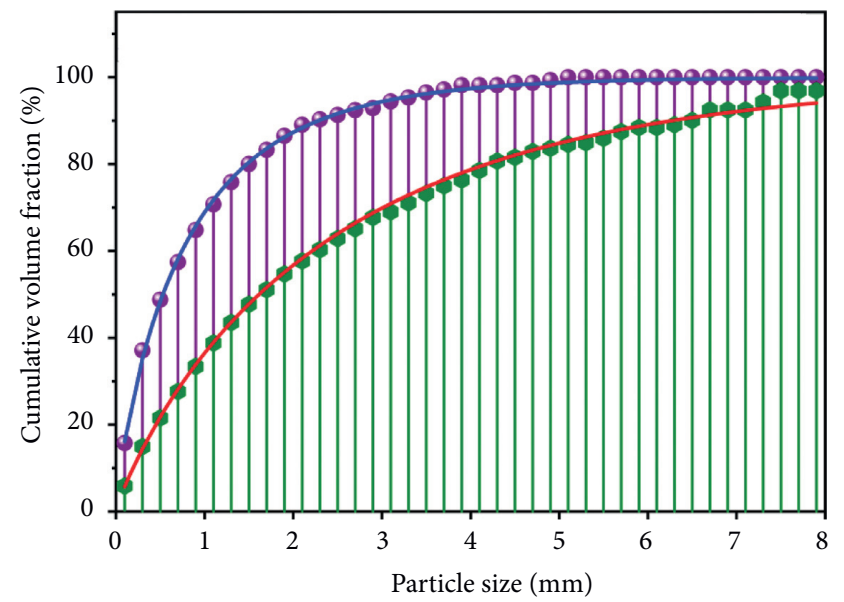

- After test

$-y=100-100^{*} \exp \left(-(x / 0.8273)^{\wedge} 0.8352\right.$

- Before test

$-y=100-100^{*} \exp \left(-(x / 2.4433)^{\wedge} 0.8994\right.$

(d)

Figure 9: The cumulative distribution before and after the tests. (a) 1 \# coal sample. (b) 2 \# coal sample. (c) 3 \# coal sample. (d) 4 \# coal sample.

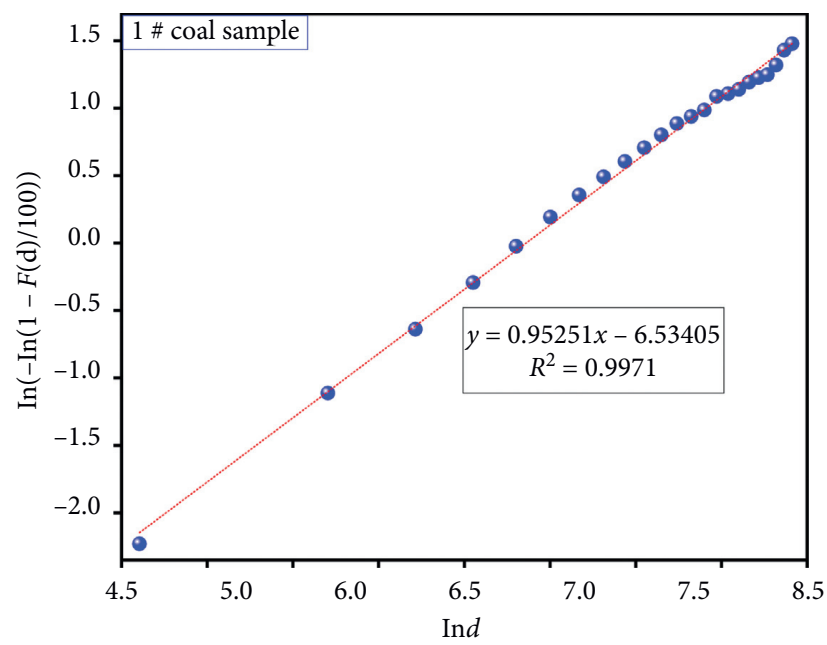

FIGURE 10: Cumulative particle size distribution and fitting results for 1 \# coal sample after the test. 
TABLE 3: Fitting parameters of Rosin-Rammler distribution.

\begin{tabular}{|c|c|c|c|c|c|c|c|c|}
\hline \multirow[b]{2}{*}{ Samples } & \multicolumn{4}{|c|}{ Before test } & \multicolumn{4}{|c|}{ After test } \\
\hline & $m$ & $m \ln d_{0}$ & $d_{0}$ & $R^{2}$ & $m$ & $m \ln d_{0}$ & $d_{0}$ & $R^{2}$ \\
\hline $\begin{array}{l}1 \text { \# coal sample } \\
2 \text { \# coal sample }\end{array}$ & 0.8577 & 6.6383 & 2.2972 & 0.9906 & $\begin{array}{l}0.9525 \\
0.9781\end{array}$ & $\begin{array}{l}6.5341 \\
6.6194\end{array}$ & $\begin{array}{l}0.9533 \\
0.8695\end{array}$ & $\begin{array}{l}0.9989 \\
0.9961\end{array}$ \\
\hline $\begin{array}{l}3 \text { \# coal sample } \\
4 \text { \# coal sample }\end{array}$ & 0.8994 & 7.0159 & 2.4433 & 0.9976 & $\begin{array}{l}0.8834 \\
0.8352\end{array}$ & $\begin{array}{l}5.9926 \\
5.6107\end{array}$ & $\begin{array}{l}0.8835 \\
0.8273\end{array}$ & $\begin{array}{l}0.9984 \\
0.9974\end{array}$ \\
\hline
\end{tabular}

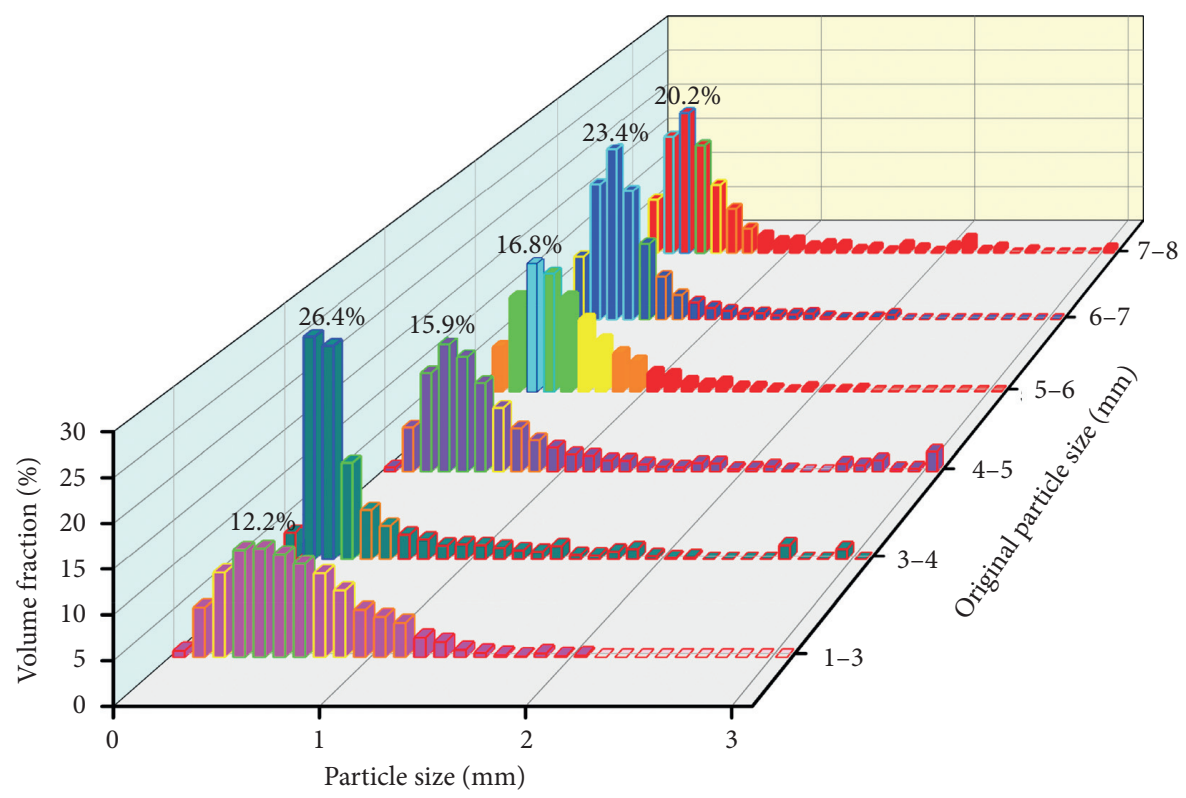

FIgURE 11: The distribution of particle size after the tests of single particle coal sample. The volume fraction represents Feret's minimum diameter volume distribution.

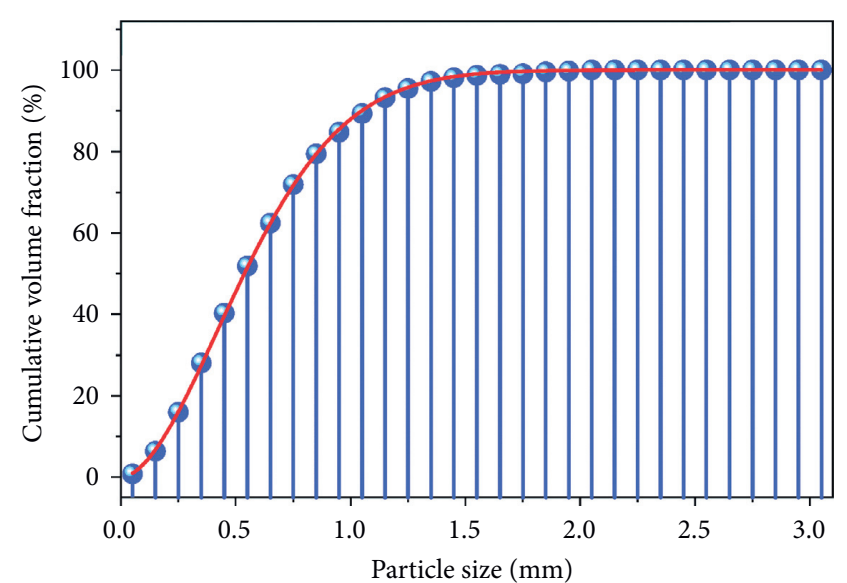

- After test

$-y=100-100^{*} \exp \left(-(x / 0.6795)^{\wedge} 1.7953\right.$

(a)

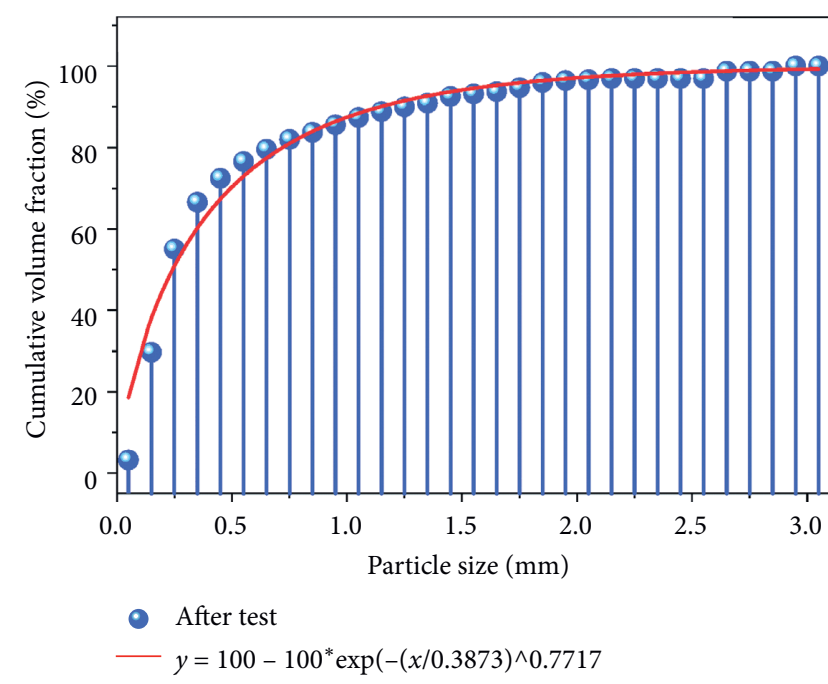

(b)

Figure 12: Continued. 


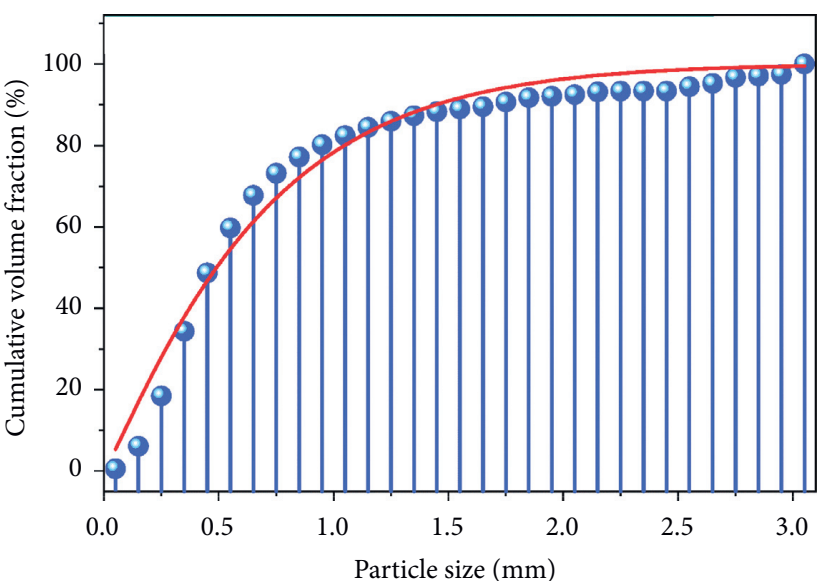

- After test

$-y=100-100^{*} \exp \left(-(x / 0.8021)^{\wedge} 1.1094\right.$

(c)

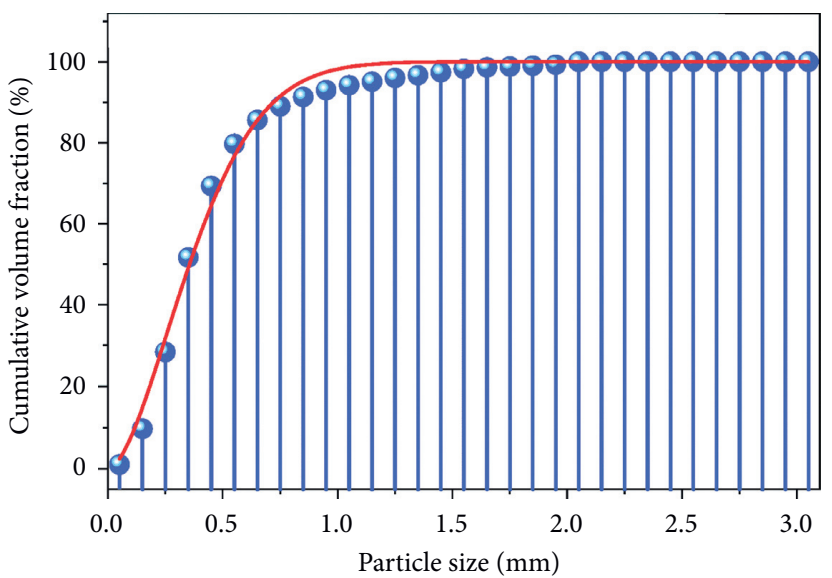

- After test

$-y=100-100^{*} \exp \left(-(x / 0.4406)^{\wedge} 1.6961\right.$

(e)

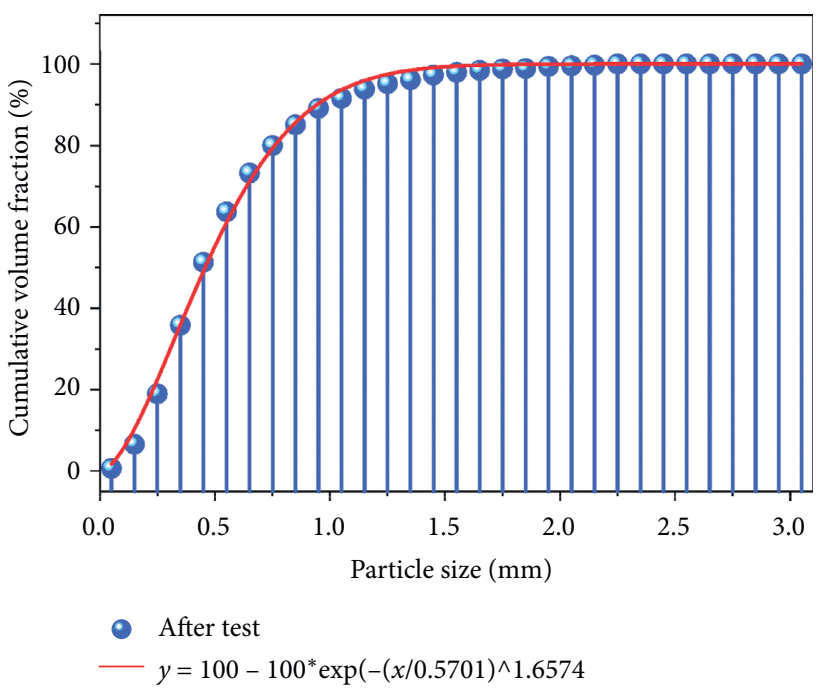

(d)

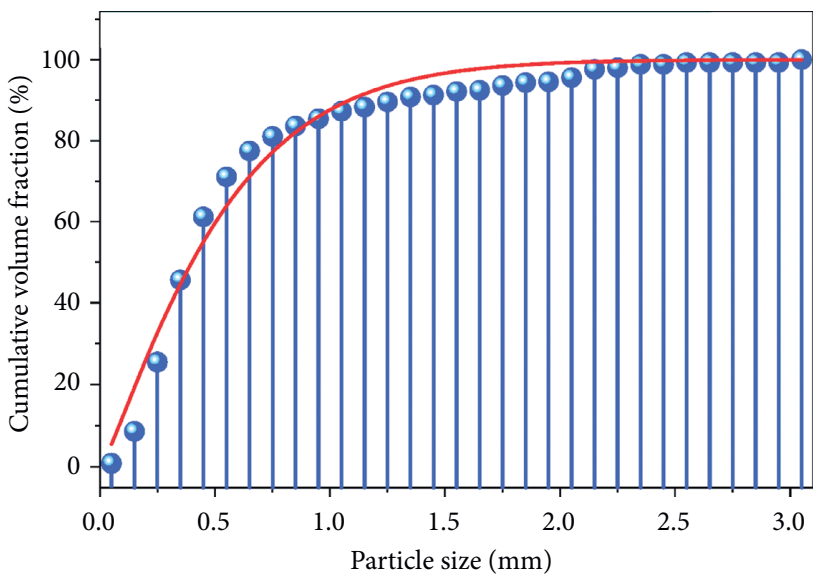

- After test

$-y=100-100^{*} \exp \left(-(x / 0.5420)^{\wedge} 1.2022\right.$

(f)

Figure 12: The cumulative distribution of particle size after the tests of single particle coal sample. (a) Original size: $1-3 \mathrm{~mm}$. (b) Original size: 3-4 mm. (c) Original size: $4-5 \mathrm{~mm}$. (d) Original size: $5-6 \mathrm{~mm}$. (e) Original size: $6-7 \mathrm{~mm}$. (f) Original size: 7-8 mm.

TABLE 4: Fitting parameters of Rosin-Rammler distribution.

\begin{tabular}{lcccr}
\hline & & \multicolumn{2}{c}{ After test } & $d_{0}$ \\
Samples & $m$ & $m \ln d_{0}$ & 0.6795 & 0.9998 \\
$1-3 \mathrm{~mm}$ & 1.7953 & 11.7079 & 0.3873 & 0.9685 \\
$3-4 \mathrm{~mm}$ & 0.7717 & 4.5987 & 0.8021 & 0.9726 \\
$4-5 \mathrm{~mm}$ & 1.1094 & 7.4188 & 0.5701 & 0.9969 \\
$5-6 \mathrm{~mm}$ & 1.6574 & 10.5177 & 0.4406 & 0.9905 \\
$6-7 \mathrm{~mm}$ & 1.6961 & 10.3262 & 0.5420 & 0.9742 \\
$7-8 \mathrm{~mm}$ & 1.2022 & 7.5682 & & \\
\hline
\end{tabular}

\section{Conclusions}

(1) In this study, change rules of pressure and coal particle size in an air reverse circulation sampling pipeline were experimentally evaluated. The results show that the sampling process could be divided into four stages: no flow field stage, sample outburst stage, stable conveying stage, and tail purging stage. In the actual sampling process, the sample collection can be started during stable conveying stage, as the pressure in the pipeline tends to be stable in this stage. The duration of outburst stage is negatively correlated 
with particle size, and that of stable conveying stage is positively correlated with particle size. The extreme pressure in the pipeline occurs in the sample outburst stage, and the extreme pressure increases first and then decreases with the increase of particle size.

(2) The particle size changed significantly in the process of gas reverse circulation sampling due to particleparticle and particle-tube wall collision. Comparing the particle size distribution before and after the test, it is found that the proportion of $1-3 \mathrm{~mm}$ coal sample changes the least. Therefore, coal sample with particle size of $1-3 \mathrm{~mm}$ is recommended for gas content measurement.

(3) The particle size distribution presents a left skewed distribution, and the cumulative distribution follows Rosin-Rammler distribution. After the test, the value of $d_{0}$ reduces more than $50 \%$, which reflects that more than half of the coal sample particles are less than $1 \mathrm{~mm}$ in diameter due to particle breakage. Further study reveals that the impact crushing degree of uniform single size particles is more serious than that of mixed coal samples.

These results are helpful to understand the factors affecting gas loss during gas reverse circulation sampling and thus provide insights for establishing a more accurate compensation model of gas loss.

\section{Data Availability}

The data used to support the findings of this study are available from the corresponding author upon request.

\section{Conflicts of Interest}

The authors declare that there are no conflicts of interest regarding the publication of this paper.

\section{Acknowledgments}

The authors acknowledge the relevant coal mine for providing the desired coal samples for this study. This work was supported by the National Key Research and Development Plan of China (2018YFC0808001), Major National Science and Technology Project of China (2016ZX05045-006-001), and Innovation Project of Tiandi Science \& Technology Co., Ltd. (2020-TD-QN014).

\section{References}

[1] R. M. Flores, "Coalbed methane: from hazard to resource," International Journal of Coal Geology, vol. 35, no. 1-4, pp. 3-26, 1998.

[2] S. Zhi and D. Elsworth, "The role of gas desorption on gas outbursts in underground mining of coal," Geomechanics and Geophysics for Geo-Energy and Geo-Resources, vol. 2, no. 3, pp. 151-171, 2016.

[3] W. P. Diamond and S. J. Schatzel, "Measuring the gas content of coal: a review," International Journal of Coal Geology, vol. 35, no. 1-4, pp. 311-331, 1998.
[4] S. Xue and L. Yuan, "The use of coal cuttings from underground boreholes to determine gas content of coal with direct desorption method," International Journal of Coal Geology, vol. 174, no. 3, pp. 1-7, 2017.

[5] L. Wang, L.-B. Cheng, Y.-P. Cheng et al., "A new method for accurate and rapid measurement of underground coal seam gas content," Journal of Natural Gas Science and Engineering, vol. 26, no. 8, pp. 1388-1398, 2015.

[6] P. G. Sevenster, "Diffusion of gases through coal," Fuel, vol. 38, no. 4, pp. 403-418, 1959.

[7] S. P. Nandi and P. L. Walker, "Activated diffusion of methane from coals at elevated pressures," Fuel, vol. 54, no. 2, pp. 81-86, 1975.

[8] R. M. Barrer, Diffusion in and through Solid, Cambridge University Press, London, UK, 1951.

[9] K. Winter and H. Janas, "Gas emission characteristics of coal and methods of determining the desorbable gas content by means of desorbometers," in Proceedings of the XIV International Conference of Coal Mine Safety Research, Wollongong, Australia, August 1996.

[10] B. A. Bolt and J. A. Innes, "Diffusion of carbon dioxide from coal," Fuel, vol. 38, pp. 333-337, 1959.

[11] E. M. Airey, "Gas emission from broken coal. an experimental and theoretical investigation," International Journal of Rock Mechanics and Mining Sciences \& Geomechanics Abstracts, vol. 5, no. 6, pp. 475-494, 1968.

[12] D. Zhao, C. Zhang, H. Chen, and Z. Feng, "Experimental study on gas desorption characteristics for different coal particle sizes and adsorption pressures under the action of pressured water and superheated steam," Journal of Petroleum Science and Engineering, vol. 179, no. 5, pp. 948-957, 2019.

[13] Q. Long, Q. Hu, Z. Zhang, and T. Ren, “On factors affecting coalbed gas content measurement," Measurement, vol. 121, no. 2, pp. 47-56, 2018.

[14] F. Wang, Y. Liang, X. Li, L. Li, J. Li, and Y. Chen, “Orthogonal experimental study on multifactor conditions for gas desorption in coal," Advances in Civil Engineering, vol. 2019, pp. 1-12, 2019.

[15] Y. P. Qin, Y. J. Hao, P. Liu, and J. Wang, "Coal particle gas desorption experiment and numerical simulation in enclosed space," Meitan Xuebao/journal of the China Coal Society, vol. 40, no. 1, pp. 87-92, 2015.

[16] X. Chen, Z. Duan, L. Yang, and W. Peng, "Experiment study on diffusion features of gassy coal under negative pressure environment," Coal Science \& Technology, vol. 44, pp. 106110, 2016.

[17] W. Zhao, K. Wang, Y. Cheng, S. Liu, and L. Fan, "Evolution of gas transport pattern with the variation of coal particle size: kinetic model and experiments," Powder Technology, vol. 367, pp. 336-346, 2020.

[18] X. C. Li, Z. B. Li, T. Ren et al., "Effects of particle size and adsorption pressure on methane gas desorption and diffusion in coal," Arabian Journal of Geosciences, vol. 12, no. 24, pp. 1-17, 2019.

[19] J. E. Hilton and P. W. Cleary, "The influence of particle shape on flow modes in pneumatic conveying," Chemical Engineering Science, vol. 66, no. 3, pp. 231-240, 2011.

[20] Y. Y. Feng, W. Yang, and W. Chu, "Coalbed methane adsorption and desorption characteristics related to coal particle size," Chinese Physics B, vol. 25, no. 6, pp. 1-10, 2016.

[21] M. Yi, Y. Cheng, Z. Wang, C. Wang, B. Hu, and X. He, "Effect of particle size and adsorption equilibrium time on pore structure characterization in low pressure N2 adsorption of 
coal: an experimental study," Advanced Powder Technology, vol. 31, no. 10, pp. 4275-4281, 2020.

[22] Y. N. Jia, Z. H. Wen, and J. P. Wei, "Experimental study on gas desorption laws of coal samples with different particle size," Safety in Coal Mines, vol. 44, no. 3, pp. 1-3, 2013.

[23] P. L. Cao, Y. W. Chen, M. M. Liu, B. Y. Chen, and J. S. Wang, "Analytical and experimental study of a reverse circulation drill bit with an annular slit," Advances in Mechanical Engineering, vol. 8, no. 9, pp. 1-10, 2016.

[24] A. Anantharaman, A. Cahyadi, K. Hadinoto, and J. W. Chew, "Impact of particle diameter, density and sphericity on minimum pickup velocity of binary mixtures in gas-solid pneumatic conveying," Powder Technology, vol. 297, pp. 311-319, 2016.

[25] J. Wei, H. Zhang, Y. Wang, Z. Wen, B. Yao, and J. Dong, "The gas-solid flow characteristics of cyclones," Powder Technology, vol. 308, pp. 178-192, 2017.

[26] S. Akhshik and M. Rajabi, "CFD-DEM modeling of cuttings transport in underbalanced drilling considering aerated mud effects and downhole conditions," Journal of Petroleum Science and Engineering, vol. 160, pp. 229-246, 2018.

[27] L. H. Zhu, Y. Huang, R. H. Wang, and J. Y. Wang, "A mathematical model of the motion of cutting particles in reverse circulation air drilling," Applied Mathematics and Computation, vol. 256, pp. 192-202, 2015.

[28] P. Cao, Y. Chen, M. Liu, and B. Chen, "Optimal design of novel drill bit to control dust in down-the-hole hammer reverse circulation drilling," Arabian Journal for Science and Engineering, vol. 43, no. 3, pp. 1313-1324, 2018.

[29] Y. Luo, J. Peng, L. Li et al., "Development of a specially designed drill bit for down-the-hole air hammer to reduce dust production in the drilling process," Journal of Cleaner Production, vol. 112, pp. 1040-1048, 2016.

[30] N. Vishnoi and S. K. Mohapatra, "Study of particle size distribution of pulverized coals in utility boilers," Particulate Science and Technology, vol. 36, no. 8, pp. 999-1005, 2018.

[31] U. Ulusoy and C. Igathinathane, "Particle size distribution modeling of milled coals by dynamic image analysis and mechanical sieving," Fuel Processing Technology, vol. 143, pp. 100-109, 2016. 